\title{
RESENHA DA TESE: RELAÇÃO PROFESSOR-MATERIAIS CURRICULARES EM EDUCAÇÃO MATEMÁTICA: UMA ANÁLISE A PARTIR DE ELEMENTOS DOS RECURSOS DO CURRÍCULO E DOS RECURSOS DOS PROFESSORES
}

\author{
Douglas Ribeiro Guimarães ${ }^{1}$
}

Esse texto objetiva fazer uma resenha a respeito da tese desenvolvida por Kátia Cristina Lima Santana, doutora em Educação Matemática pela Pontifícia Universidade Católica de São Paulo que defende sua tese em 2017, sob orientação da Prof ${ }^{a}$. Dra ${ }^{\mathrm{a}}$. Ana Lúcia Manrique. A autora hoje, atua como professora adjunta na Universidade Federal do Recôncavo da Bahia (UFRBA) ${ }^{2}$.

A autora inicia sua tese se apresentando e explica os caminhos percorridos, desde mudanças de grupos de pesquisa até a metodologia e organização da pesquisa, discorrendo sobre sua dissertação e um projeto do grupo "Professor de Matemática: Formação, Profissão, Saberes e Trabalho Docente", que deram origem a sua tese. Nesse momento a autora também indica a opção da escrita da tese em primeira pessoa do plural, pois leva em consideração as diversas participações do grupo de pesquisa e os autores que fundamentam o estudo.

O tema da tese é investigar as relações que podem ser estabelecidas entre os recursos dos professores de matemática e os recursos dos materiais curriculares, realizando uma abordagem metodológica qualitativa com estudo teórico bibliográfico e metanálise. Os materiais que Santana (2017) está considerando podem ser impressos ou online, principalmente os utilizados continuamente pelos professores e alunos, ou seja, livros didáticos, materiais apostilados, podendo ser elaborados pelas secretarias de educação, ONGs, editoras, além de cadernos de atividades ou de apoio.

Na revisão de literatura são identificados três Programas de Pós-graduação que se concentram nos estudos sobre a relação professor-material curricular, para cada Programa

\footnotetext{
${ }^{1}$ Licenciado em Matemática pela Universidade Estadual Paulista “Júlio de Mesquita Filho" (UNESP/Rio Claro). Mestrando em Educação Matemática pela mesma instituição, Rio Claro, São Paulo, Brasil. E-mail: douglasrguimaraes@ hotmail.com

${ }^{2}$ Informação retirada no Currículo Lattes, disponível em: http://lattes.cnpq.br/1477492244336505. Acesso em: 25 jan. 2020.
} 
DOI: http://dx.doi.org/10.33238/ReBECEM.2020.v.4.n.1.24057

é elaborado um quadro que expõe o nome do pesquisador, o título da pesquisa e o ano de início ou conclusão da dissertação ou tese, levando para a seguinte situação:

[...] trabalhos desenvolvidos na UFBA-UEFS focam nos materiais curriculares de modelagem matemática em ambientes virtuais, as investigações desenvolvidas na UFMS concentram-se na interação com os livros didáticos e os estudos desenvolvidos na PUC-SP envolvem diferentes tipos de materiais curriculares (SANTANA, 2017, p. 24).

Destaca-se o fato das pesquisas revisadas nestes três Programas serem influenciadas pelos estudos de Remillard ${ }^{3}$ e seus colaboradores, e, ainda, que as pesquisas sobre a relação dos professores com materiais curriculares “[...] não produzem uma base teórica e conceitual [...] o que poderia ser uma importante base para a construção de um campo de pesquisa" (SANTANA, 2017, p. 25). Esta revisão mostra a relevância da pesquisa aqui resenhada, contribuindo para a área da Educação Matemática.

Após esclarecer algumas das diversas concepções de currículo, Santana (2017) utiliza os termos de Sacristán ${ }^{4}$ (2000), que propõe seis níveis, momentos ou fases de objetivação do currículo no processo de seu desenvolvimento: currículo prescrito, currículo apresentado (aos professores), currículo moldado (pelos professores), currículo em ação, currículo realizado e currículo avaliado. Dessa forma, para entender a relação do professor com os materiais curriculares, segue-se o chamado currículo apresentado, além de conceber o professor como um designer ativo do currículo, como falam Remillard $^{5}$ (2005) e Brown ${ }^{6}$ (2009).

Ainda em referência na relação professor-materiais curriculares, a autora se apoia no modelo The Design Capacity for Enactment (DCE) ${ }^{7}$ proposto por Brown (2009), em que se faz necessária a análise dos recursos curriculares (objetos físicos, representações de domínio e procedimentos) e os recursos dos professores (conhecimento do conteúdo, conhecimento pedagógico do conteúdo, crenças e objetivos) para entender essa relação. Segundo Santana (2017), este modelo

\footnotetext{
${ }^{3}$ REMILLARD, J. T.; HERBEL-EISENMANN, B. A.; LLOYD, G. M. (Ed.). Mathematics Teachers at Work: connecting curriculum materials and classroom instruction. New York: Taylor \& Francis, 2009.

${ }^{4}$ SACRISTÁN, J. G. O currículo: uma reflexão sobre a prática. Tradução: Ernani F. da Fonseca Rosa. 3. ed. Porto Alegre: Artmed, 2000.

5 REMILLARD, J. T. Examining key concepts in research on teachers'use of Mathematics Curricula. Review of Educational Research, Washington, American Educational Research Association, v. 75, n. 2, p. 211-246, jun. 2005.

${ }^{6}$ BROWN, M. W. The Teacher-Tool Relationship: theorizing the design and use of curriculum materials. In: REMILLARD, J. T.; HERBEL-EISENMANN, B. A.; LLOYD, G. M. (Ed.). Mathematics Teachers at Work: connecting curriculum materials and classroom instruction. New York: Taylor \& Francis, 2009. p. $17-36$.

${ }^{7}$ Santana (2017) mantém a opção de não traduzir este modelo, contudo, não faz menção aos motivos dessa escolha.
} 
[...] caracteriza e explica as diferentes práticas em que o professor se envolve ao desenvolver suas aulas a partir de materiais curriculares e ajuda a compreender e caracterizar as capacidades dos professores em perceber e mobilizar os recursos existentes, a fim de criar contextos de ensino. Também expõe os elementos que os materiais curriculares trazem para a relação com os professores, delimitando diferentes tipos de usos (SANTANA, 2017, p. 32).

Após essas considerações, o objetivo da pesquisa é "analisar e refletir sobre a relação professor-material curricular a partir de elementos que compõem os recursos do currículo e os recursos de professores que ensinam Matemática”.

A metodologia empregada se enquadra na pesquisa qualitativa, uma vez que para Santana (2017, p. 36, grifos meus) sua pesquisa busca "[...] compreender o papel dos materiais curriculares na interação dinâmica entre os artefatos e os professores que os utilizam, bem como por estarmos interessados em entender como esse uso se dá". $\mathrm{O}$ destaque aos verbos na referência anterior encontra respaldo em Bicudo e Costa (2019, p. 14, grifos dos autores), para quem: "um modo mais simples e direto de se entender a lógica subjacente à investigação quantitativa e à qualitativa seja focar os verbos explicar e compreender". Ainda, na estrutura da tese, apresenta-se três objetivos específicos atrelados as três questões de pesquisa, sendo que cada um dos objetivos se relaciona a respectiva questão e tem uma forma procedimental de análise e estudo próprio, conforme o Quadro 1.

Quadro 1: Síntese da organização da tese

\begin{tabular}{|c|c|c|c|}
\hline $\begin{array}{l}\text { Objetivos } \\
\text { específicos }\end{array}$ & $\begin{array}{c}\text { (1) Refletir sobre } \\
\text { referenciais analíticos para } \\
\text { analisar materiais } \\
\text { curriculares e abordar } \\
\text { elementos que possam } \\
\text { potencializar a mobilização } \\
\text { de conhecimentos dos } \\
\text { professores que ensinam } \\
\text { Matemática. }\end{array}$ & $\begin{array}{l}\text { (2) Identificar } \\
\text { conhecimentos } \\
\text { mobilizados por } \\
\text { professores que } \\
\text { ensinam Matemática ao } \\
\text { interagir com materiais } \\
\text { curriculares. }\end{array}$ & $\begin{array}{l}\text { (3) Analisar a relação } \\
\text { entre os usos que } \\
\text { professores fazem dos } \\
\text { materiais curriculares } \\
\text { de Matemática e os } \\
\text { conhecimentos } \\
\text { docentes favorecidos a } \\
\text { partir dessa relação. }\end{array}$ \\
\hline Tipo de pesquisa & Qualitativa & Qualitativa & Qualitativa \\
\hline $\begin{array}{l}\text { Procedimento de } \\
\text { estudo }\end{array}$ & $\begin{array}{l}\text { Estudo teórico do tipo } \\
\text { bibliográfico }\end{array}$ & Metanálise & Metanálise \\
\hline Coleta de dados & $\begin{array}{c}\text { Próprias ideias, } \\
\text { constructos, teorias } \\
\text { envolvidas na condução da } \\
\text { pesquisa }\end{array}$ & Relatório de pesquisa & Relatório de pesquisa \\
\hline $\begin{array}{l}\text { Procedimento de } \\
\text { análise dos dados } \\
\text { e/ou produto }\end{array}$ & $\begin{array}{l}\text { Quadro analítico para } \\
\text { materiais curriculares }\end{array}$ & Categorias a posteriori & $\begin{array}{c}\text { Categorias que } \\
\text { emergem dos dados }\end{array}$ \\
\hline
\end{tabular}

Fonte: Santana (2017, p. 41)

Infere-se que as primeiras palavras dos objetivos específicos (refletir, identificar e analisar) são verbos característicos de uma pesquisa qualitativa, contudo, ressalvas precisam ser feitas, trazendo novamente o que seria compreender nas palavras de Bicudo 
DOI: http://dx.doi.org/10.33238/ReBECEM.2020.v.4.n.1.24057

e Costa (2019, p. 16), para quem o pensar filosófico está presente e vai além desses verbos: "A incompletude do compreendido, a constante insatisfação do humano com as respostas já dadas, o horizonte aberto a outras perguntas e outros discursos: essa é a caminhada da compreensão".

A escrita da tese é desenvolvida no formato multipaper, ou seja, um compilado de artigos independentes e publicáveis, porém, contam com um fio condutor que segue o objetivo geral da pesquisa - analisar e refletir sobre a relação professor-material curricular -, além de conter a introdução e considerações finais que os unem. São apresentados três artigos, cada um relacionado ao objetivo específico observado no Quadro 1. Santana (2017) mostra as vantagens deste formato, como a acessibilidade aos textos, produtividade e publicação, contudo, aparecem algumas desvantagens, por exemplo, uma ideia de fragmentação e a sobreposição dos artigos, por ser inevitável a repetição de conceitos, ideias ou argumentos em cada um deles, o que, de fato, acontece.

O primeiro artigo traz destaque a três referenciais de análise de materiais curriculares, abordando as características dos materiais (DAVIS; KRAJCIK, 2005) ${ }^{8}$, as categorizações (STEIN; KIM, 2009) ${ }^{9}$, e um quadro de análise (FONSECA, 2013) ${ }^{10}$, tal que os dois primeiros têm relação com as oportunidades de aprendizagem do professor (inclusão de narrativas e formas de conversa dos elaboradores dos materiais com o professor). Encerrando o artigo, a autora propõe um quadro analítico para materiais curriculares com base nas discussões dos três referenciais. O quadro apresentado inclui nove categorias e 19 subcategorias, identificando diversos elementos presentes nos materiais curriculares, servindo como base para o trabalho dos professores e possíveis reflexões.

No segundo artigo são tomados aportes teóricos sobre a relação professor-material curricular e o modelo do conhecimento didático-matemático do professor, realizando uma metanálise sobre um relatório de projeto de pesquisa (2011-2012) onde professores da rede pública avaliaram materiais curriculares de Matemática. Santana (2017) mostra que os professores reproduzem, adaptam e improvisam os materiais curriculares em sala de

\footnotetext{
${ }^{8}$ DAVIS, E.; KRAJCIK, J. Designing Educative Curriculum Materials to Promote Teacher Learning. Educational Researcher, v. 34, n. 3, p. 3-14, 2005.

${ }^{9}$ STEIN, M. K.; KIM, G. The Role of Mathematics Curriculum Materials in Large-Scale Urban Reform: An Analysis of Demands and Opportunities for Teacher Learning. In: REMILLARD, J. T.; HERBELEISENMANN, B. A.; LLOYD, G. M. (Ed.). Mathematics Teachers at Work: Connecting curriculum materials and classroom instruction. New York: Taylor \& Francis, 2009. p. 37-55.

${ }^{10}$ FONSECA, C. I. T. T. R. As funções exponencial e logarítmica nos manuais escolares do $12 .^{\circ}$ ano. 2013. 165 f. Dissertação (Mestrado em Didática) - Departamento de Educação, Universidade de Aveiro, Portugal, 2013.
} 
DOI: http://dx.doi.org/10.33238/ReBECEM.2020.v.4.n.1.24057

aula. A autora não sintetiza os aportes teóricos em quadros, o que poderia facilitar a compreensão do texto, uma vez que ao defini-los, surgem diversas categorias que se complementam. Ao trazer excertos dos professores fica claro como os mesmos fazem para reproduzir, adaptar e improvisar as atividades.

O terceiro artigo tem diversas referências ao segundo, desde os aportes teóricos até o próprio cenário de análise (projeto de pesquisa), e as diferenças evidenciadas são que os professores utilizam os materiais curriculares como fonte para seus conhecimentos, tanto matemáticos quanto práticas pedagógicas novas, surgindo assim, possibilidades para que a elaboração desses materiais mostrem recursos que potencializam e favoreçam os conhecimentos dos professores.

Nas considerações finais, uma breve retrospectiva de todo o trabalho é apresentada, seguindo para ponderações: dos recursos curriculares (quadro analítico); dos recursos dos professores (reproduzir, adaptar e improvisar); dos recursos curriculares e dos recursos dos professores (fonte para o conhecimento matemático e pedagógico dos professores). Encerrando a tese, Santana (2017) elabora um quadro, ampliando o The Design Capacity for Enactment (DCE) proposto por Brown (2009), complementando-o com sua pesquisa, e, para futuras pesquisas, propõe investigar quais outros fatores interferem na relação professor-materiais curriculares; quais recursos os estudantes mobilizam nessa relação; aspectos do contexto onde a escola está inserida, entre outras questões.

A opção de escrever uma tese em formato de artigos ainda necessita de discussões e reflexões, não cabendo dizer que essa escolha é melhor ou pior do que as escritas tradicionais de pesquisas, e sim que ela é diferente. Isto porque os argumentos utilizados sobre produtividade e publicação parecem reforçar um discurso de que quanto mais se publica maior o reconhecimento do pesquisador. Entretanto, as dificuldades que muitos têm ${ }^{11}$ em ler uma Tese de Doutorado ou livros robustos podem começar a serem "superadas" com a acessibilidade aos artigos encontrados nas teses multipaper. Assim, essas discussões e reflexões são necessárias para evitar preconceitos e tentativas de rebaixar ou exaltar determinada forma de escrita.

Por fim, é notável a relevância da pesquisa aqui resenhada, principalmente por ser um ponto de partida para estudar as relações dos professores com materiais curriculares

\footnotetext{
${ }^{11}$ Refiro-me aos pesquisadores iniciantes, como eu, mas o foco aqui não é generalizar ou depreciar esse grupo.
} 
DOI: http://dx.doi.org/10.33238/ReBECEM.2020.v.4.n.1.24057

e a elaboração de um quadro para a análise de tal relação. São necessárias mais investigações sobre esse tema, visto que esses materiais fazem parte de quase todas as salas de aula, com foco em aulas de Matemática. Compreender essa relação pode revelar aspectos sobre o processo de ensino e aprendizagem da Matemática.

\section{Referências}

BICUDO, M. A. B; COSTA, A. P. (org.). Leituras em pesquisa qualitativa. São Paulo: Editora Livraria da Física, 2019.

SANTANA, K. C. L. Relação professor-materiais curriculares em Educação Matemática: uma análise a partir de elementos dos recursos do currículo e dos recursos dos professores. 2017. Tese (Doutorado em Educação Matemática) - Faculdade de Ciências Exatas e Tecnologia, Pontifícia Universidade Católica de São Paulo, São Paulo, 2017.

Recebido em: 16 de fevereiro de 2020

Aceito em: 17 de abril de 2020 